\title{
Fluorescent Protein-Based Indicators for Functional Super-Resolution Imaging of Biomolecular Activities in Living Cells
}

\author{
Kai Lu ${ }^{1}$, Cong Quang Vu ${ }^{2}$, Tomoki Matsuda ${ }^{1}$ and Takeharu Nagai ${ }^{1,2, *}$ \\ 1 The Institute of Scientific and Industrial Research, Osaka University, Ibaraki 567-0047, Japan; \\ ka1@sanken.osaka-u.ac.jp (K.L.); tmatsuda@sanken.osaka-u.ac.jp (T.M.) \\ 2 Graduate School of Frontier Biosciences, Osaka University, Suita, Osaka 565-0871, Japan; \\ v9c40@sanken.osaka-u.ac.jp \\ * Correspondence: ng1@sanken.osaka-u.ac.jp; Tel.: +81-6-6879-8481
}

Received: 25 October 2019; Accepted: 15 November 2019; Published: 17 November 2019

\begin{abstract}
Super-resolution light microscopy (SRM) offers a unique opportunity for diffraction-unlimited imaging of biomolecular activities in living cells. To realize such potential, genetically encoded indicators were developed recently from fluorescent proteins (FPs) that exhibit phototransformation behaviors including photoactivation, photoconversion, and photoswitching, etc. Super-resolution observations of biomolecule interactions and biochemical activities have been demonstrated by exploiting the principles of bimolecular fluorescence complementation (BiFC), points accumulation for imaging nanoscale topography (PAINT), and fluorescence fluctuation increase by contact (FLINC), etc. To improve functional nanoscopy with the technology of genetically encoded indicators, it is essential to fully decipher the photo-induced chemistry of FPs and opt for innovative indicator designs that utilize not only fluorescence intensity but also multi-parametric readouts such as phototransformation kinetics. In parallel, technical improvements to both the microscopy optics and image analysis pipeline are promising avenues to increase the sensitivity and versatility of functional SRM.
\end{abstract}

Keywords: fluorescent protein; GFP; photochemistry; phototransformation; genetically encoded indicator; BiFC; PAINT; FRET; super-resolution microscopy; nanoscopy

\section{Introduction}

The advent of fluorescent proteins (FPs) is a unique case of biotechnology development and a manifestation of "seeing is believing." The jellyfish Aequorea Victoria green fluorescence protein (GFP) was first discovered many decades ago, and its gene was cloned in the 1990s. The evolutionary significance and biological function of this peculiar protein were all but a mystery at the time (it was later found that GFP can be a light-induced electron donor, etc.) [1]. Nevertheless, the fluorescence of GFP proved to be highly utilitarian for in situ labeling of cells and proteins [2,3]. Thus the hunt for new FP templates in light-emitting organism began, and mutations that improve fluorescence properties were actively sought after via molecular evolution in laboratories. Today, the FP family has expanded to cover the light spectrum from ultraviolet (UV) to near infrared, bearing fruits of bright and environmentally stable FPs suitable for various bioimaging applications [4]. Although competing technologies of fluorescent labeling kept emerging, the popularity of FPs has never diminished. Compared to chemical dyes and quantum dots, FPs can be genetically encoded, i.e., expressed within target cells as transgenes. The versatility brought forward by genetic encoding is not to be understated. First and foremost, intracellular proteins can be easily visualized in living cells 
through FP fusion. Beyond that, FP expression can be toggled with inducible promoters, e.g., via the tetracycline (Tet)-controlled expression system. Endogenous proteins can be labelled with genome editing tools such as zinc finger nucleases, transcription activator-like effector nuclease (TALEN) and clustered regularly interspaced short palindromic repeats (CRISPR). Gene activation or silencing can be monitored with tissue-specific or pathologically regulated promoters, etc. Although some fluorescent dyes can be ligated to genetically encoded peptides (e.g., Halo-, SNAP- and CLIP-tags), caveats such as nonspecific binding, cytotoxicity, and poor ligand permeability pose challenges for live-cell imaging applications [5].

Apart from using FPs as light-emitting labels, it is possible to engineer genetically encoded indicators to report biomolecular activities with fluorescence changes. In 1997, Miyawaki et al. developed a chimeric protein that fluoresces in response to intracellular calcium ions [6]. To enable calcium imaging, a $\mathrm{Ca}^{2+}$-binding calmodulin-M13 hybrid domain is sandwiched strategically between two GFP-derived FPs that form a Förster resonance energy transfer (FRET) pair. $\mathrm{Ca}^{2+}$ binding switches calmodulin-M13 from an extended dumb-bell-like form to a compact globular form. This conformational change pulls donor and accepter closer together and elevates the FRET. The advent of this genetically encoded $\mathrm{Ca}^{2+}$ indicator opened the new avenue of visualizing bimolecular activities in living cells. Since then, over 700 genetically encoded indicators have been developed for detecting protein behaviors and various biochemical activities, with many potent designs being brought to the table over the years. This review does not offer itself as a shortcut to the enormous goal of learning all these indicators. Neither does it aims for something as ambitious as excellence in the rational engineering of FPs and indicators. For that audience, comprehensive reviews on genetically encoded indicators exist elsewhere $[7,8]$. Instead, we aim for the eminently possible goal of understanding in a much more definite niche: namely the interface between FP-based indicators and super-resolution light microscopy (SRM).

Genetically encoded indicator technology is arguably an indispensable part of microscopy, inasmuch as biomolecular activities must be revealed in the context of cellular architecture to stay relevant. Most off-the-shelf indicators are designed with conventional fluorescence microscopy in mind and are targeted for ensemble imaging. In consequence, spatial resolution of the optical systems is limited by the physical law of light diffraction and thus caps around half of the fluorescent emission wavelength [9]. Accumulating evidence has made it increasingly clear that intracellular signaling is often segregated into discrete nanoscopic domains. Sensing biological events on such a minute scale demands improved spatial resolution of microscopes. To this end, functional SRM began to receive attentions recently [10]. Unlike canonical SRM, which aims to reveal ultrafine structural details, functional SRM attempts to extract information regarding intracellular environments and physiology from the multi-parametric super-resolved fluorescence signals. However, early implementations of functional SRM were mostly restricted to biophysical investigations of polarity [11-13] and hydrophobicity [14], etc., rather than focusing on the biology of living cells. The imaging experiments also rely heavily on fluorescent dyes [12-14], thus lack the many advantages of genetically encoded systems. This review serves as a status report that is dedicated to the newly formed alliance between FP-based indicators and SRM, toward revealing not only nano-architecture but also nano-sequestered biomolecular activities in living cells. In particular, we focus on imaging techniques that exploit phototransformation behaviors of FPs, including photoconversion, photoactivation, and photoswitching [4]. We will lay down the immediate challenges of developing indicators for diffraction-unlimited microscopy, provide examples of monitoring biomolecule interactions and biochemical activities in nanoscopic domains, and discuss how phototransformation has been exploited in unprecedented manners for bioimaging innovations transcending spatial resolution improvement. Potential target audiences are adventurous FP engineers and indicator developers keen to explore advanced imaging techniques, as well as microscopists who seek to expand nanoscopy beyond a structure visualization tool. A holistic understanding of indicator designs and SRM can be expected by the end of this review, with information and clues being provided for future advancements in this field. 


\section{Sense and Sensibility: Anatomy of Genetically Encoded Indicators}

In this review, genetically encoded indicators are defined as FP-based chimeric proteins exhibiting fluorescence sensitized to physiological or biomolecular cues. A typical indicator consists of two core elements: a sensing domain and a fluorescent reporter. The sensing domain is usually derived from endogenous proteins or peptides that are inherently sensitive towards the biological activity of interest. In the case of calcium indicators, calmodulin from the calcium signal transduction pathway is often used for recognizing calcium ions through its $\mathrm{EF}$ hand motifs $[6,15,16]$. The $\mathrm{Ca}^{2+}$-associated holo-calmodulin undergoes a conformational change and relays the information to the fluorescent reporter. Thus, calcium concentration is converted to fluorescence signals that enable microscopic observation. To sensitize the fluorescent reporter moiety for activity-dependent response and maximize dynamic range of the indicator, FPs are often subjected to further configuration such as circular permutation (cp) [16,17], reconstitution of split fragments [18], and FRET pairing [6,19]. Notably, chromophores of many FPs are sensitive to factors like $\mathrm{pH}$, temperature and ionic strength [20]. While such environmental sensitivity is normally deleterious for ubiquitous fluorescence imaging, it nevertheless becomes an exploitable feature for sensing physiological conditions inside the cell. In such applications, FPs are not only the passive reporter but also double in the active role of sensing domain. One example is the development of a pH-sensitive FP, pHVenus, by introducing a H148G mutation to the yellow FP Venus [21] and therefore intentionally unshielded the chromophore by creating a solvent channel in the cavity for higher $\mathrm{p} K_{\mathrm{a}}$, i.e., higher $\mathrm{pH}$ sensitivity [22]. For general fluorescence labeling, high pH sensitivity of FPs is undesirable and avoided. However, pHVenus found its niche and has been successfully used as an indicator for intracellular $\mathrm{pH}$ when expressed in living cells [22]. Indicators like pHVenus highlight the importance of tuning fluorescence properties for specific applications in a context-dependent manner, instead of judging the merit of FPs with a universal standard.

Besides the sheer efforts from protein engineers to continuously update the indicators, convergent evolution with microscopy is essential for expanding the possibility of this FP-based technology. Historically, epifluorescence and confocal microscopies have become the primary tools for general bioimaging purposes. However, spatial resolution of conventional microscopy is bound by Abbe's diffraction limit [9] which has since been surpassed by SRM. Regional biomolecular activities in cells tend to be both minuscule and transitory. Unsurprisingly, some fleeting phenomena are not detected by ensemble imaging. SRM provides an opportunity to lift this barrier and catch singular events which could potentially impact the overall cell function.

The most direct approach for nanoscopic observation of biomolecule activities is perhaps to reach out for the huge back catalogue of indicators. Among SRM techniques, stimulated emission depletion (STED) and structured-illumination microscopy (SIM) are, in principle, directly backward compatible with preexisting indicators made of constitutive FPs. STED excites a diffraction-limited spot but uses a second laser to deplete emission within an Airy disk, therefore producing a refined subdiffraction illumination area [23]. The final STED image is obtained by scanning a sample with the dual lasers (as opposed to common point scanning seen in confocal microscopy) that effectively narrows point spread function (PSF) of the fluorophores. Intensity information from emission, i.e., the indicator's quantitative readout, is well preserved in STED; as a result, migration from diffraction-limited microscopy to STED is straightforward in theory for imaging conventional indicators. On the down side, STED depletion beam deploys some of the highest laser power among all SRM techniques, raising concerns over phototoxicity to biological samples and unrecoverable photodestruction of FPs (phototoxicity and FP photodestruction are often loosely quoted under the collective term of photodamage). Despite that, time-lapse STED imaging in living cells has been demonstrated on several occasions [24,25]. For functional SRM, a $\mathrm{H}_{2} \mathrm{O}_{2}$ indicator based on cpYFP, named HyPer2, has been successfully observed with STED [26]. Although systematic studies of photodamage remain criminally uncommon, smart light-dose engineering could potentially be a game changer for live-cell STED, e.g., fast laser scanning and reduced dwell time allow living samples to recover viability during dark breaks of acquisition [27]. 
In addition, red-shifted fluorophores are attractive options for STED because of drastically reduced phototoxicity by up to several hundred folds over FPs excited with UV or blue light [28]. These FPs are usually derived from phytochromes or cyanobacteriochromes. They bear novel external bilin chromophores, which is a departure from the $\beta$-barrel scaffold of GFP. Recently, effective brightness and monomeric property of near-infrared biliproteins have been greatly improved to accommodate bioimaging applications in mammalian cells [29-31]. For SRM, a photostable biliprotein with far-red emission, named SNIFP, has been successfully applied to the imaging of cytoskeleton and nucleus pores in living cells (notably, low quantum yield of SNIFP is likely offset by the combination of strong laser excitation in STED and sensitive detector) [25]. Compared to STED, SIM requires less aggressive illumination scheme, and is arguably more amiable towards living samples [32]. However, standard SIM is ultimately still bound by the physics law of diffraction, so the maximum resolution improvement is only two-fold over the diffraction limit. In additional, obtaining the final SIM image requires mathematical reconstruction from raw data, a complication compared to the direct output of STED.

\section{A Tale of Two Cities: Phototransformable Indicators for Super-Resolution Fluorescence Microscopy}

Except for STED and SIM, phototransformation of fluorophores are exploited in many other SRM methods, such as photo-activated localization microscopy (PALM) [33,34], super-resolution optical fluctuation imaging (SOFI) [34,35], super-resolution radial fluctuations (SRRF) [36], Bayesian analysis of the blinking and bleaching (3B) [37], entropy-based super-resolution imaging (ESI) [38], spatial covariance reconstructive (SCORE) [39], and multiple signal classification algorithm (MUSICAL) [40]. To ease non-microscopists out of this perplexing jungle of acronyms, these techniques universally separate emitters by photo-inducing fluorophores to stochastically traverse two or more distinctive states, then approximate emitter positions through mathematical calculation, and reconstruct the super-resolved image. Notably, these techniques have different upper limits for the density of on-state fluorophores. For PALM, sparsely photoactivated fluorophores must be separated by a distance greater than the diffraction limit, thus requires strict single-molecule blinking; though some multi-emitter fitting algorithms now allow certain degree of fluorophore overlapping in single-molecule localization microscopy (SMLM), e.g., the DAOSTORM algorithm [41]. Compared to SMLM, other nanoscopies have relaxed requirement of emitter density and output super-revolved images from fluorophore fluctuation or flickering data, e.g., SOFI, SRRF and 3B. An excellent introduction of SRM can be found in a timely review by Schermelleh et al. [42], thus out of the scope of this paper. Although photochromism may also be induced in certain constitutive FPs in the presence of chemical cofactors, e.g., incubating mCherry with thiol or $\beta$-mercaptoethanol leads to reversible fluorescence off or red-to-blue emission $[43,44]$, the most non-invasive and convenient approach to introduce blinking in living cells is still by using phototransformable FPs [45-47]. Light-induced transformation phenomena that are commonly exploited in SRM include photoactivation [48,49], photoconversion [50,51], and reversible photoswitching [52-54]. Although current understanding of FP photochemistry is far from complete, it is most likely that for the GFP family, cis-trans isomerization of the chromophore coupled to protonation state changes, plays a key role in the process [55].

The majority of preexisting indicators rely on fluorescence intensity to readout the biomolecular activity of interest. However, in super-resolution imaging experiments, accurate measurement of intensity is often obscured. First, conventional microscopy takes ensemble fluorescence, which is the combined signals from many emitters and of high signal-to-noise ratio $(\mathrm{S} / \mathrm{N})$, whereas single-molecule imaging ought to work with much smaller photon budget and lower $\mathrm{S} / \mathrm{N}$, making intensity measurement especially sensitive to unevenness in background. To improve this situation, confined illumination with total internal reflection fluorescence (TIRF), highly inclined and laminated optical sheet (HILO) or light sheet are now commonplace. Red-shifted illumination also helps to reduce autofluorescence. More often than not, these tricks remain insufficient for accurately knowing the intensity of individual emitters in biological samples. Moving forward, elaborated methods for the computation and subtraction 
of local background on single-molecule level, e.g., SMALL-LABS, may help remove systematic bias in gauging fluorescence intensity on nanoscale [56]. Second, as a pitfall of post-acquisition image reconstruction, intensity of computational SRM often deviates from the typical linear response, e.g., non-linear brightness is introduced by high-order cumulant statistics in SOFI. While such sacrifice is necessary for breaking the diffraction limit, it is expected to squish the dynamic range of indicators and undermine data interpretation. Improved imaging reconstruction algorithms have emerged to relieve this issue, e.g., balanced SOFI combines information from cumulants of several different orders to linearize the fluorescence response [57], but wide adoption of such techniques in functional SRM remains uncommon, partly because of the technical complexity.

It is evident that developing indicators for SRM requires appreciation of the principles of diffraction-unlimited imaging, thus cannot be brutally forced with prior routines. While intensity-based indicators are pending a breakthrough, super-resolution biosensing has otherwise been successfully demonstrated by circumventing this limitation with nifty designs (summarized in Table 1).

\subsection{Diffraction-Unlimited Observation of Protein-Protein interactions by Bimolecular Fluorescence Complementation (BiFC) of Split Phototransformable Fluorescent Proteins}

To achieve diffraction-unlimited imaging without radical overhaul of available indicator designs, bimolecular fluorescence complementation (BiFC) has quickly become a popular strategy. These indicators are typical for detecting protein-protein interactions (PPIs), but their functionality also extends to the imaging of biochemical activities. In BiFC system, a FP is split into two parts, namely an $\mathrm{N}$-terminus fragment and its complimentary C-terminus counterpart. Neither fragments emit light independently. To develop indicators, interacting proteins of interest are fused to each FP fragments separately. When PPI occurs, the two fragments converge and undergo molecular complementation. After chromophore maturation, the reconstituted FP fluoresces and facilitates the visualization of interactions (Figure 1). Compared to indicators that rely on analogue intensity, BiFC indicators have binary readout-the two states, namely fluorescent or non-fluorescent, correspond to the presence or absence of PPI respectively.

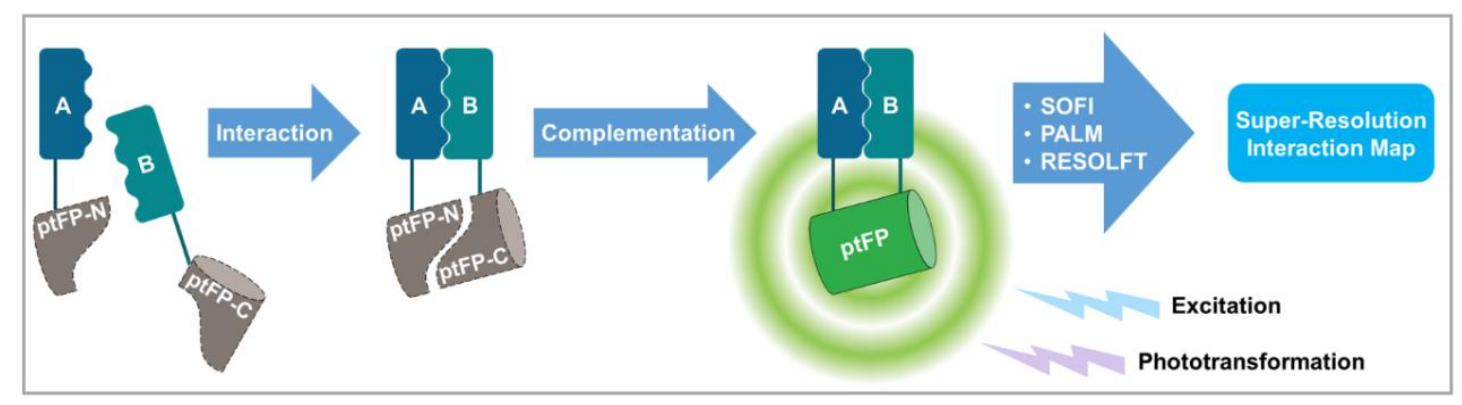

Figure 1. Principle of super-resolution imaging of protein-protein interactions with BiFC of phototransformable fluorescent proteins (ptFPs). Protein A is fused to an N-terminal fragment of the $\mathrm{ptFP}$ (ptFP-N); and protein B is fused to the complementary C-terminal fragment (ptFP-C). When protein $\mathrm{A}$ and $\mathrm{B}$ interacts, ptFP-N and ptFP-C reconstitute. Following chromophore maturation, fluorescently labeled interaction loci can be excited and phototransformed for super-resolution detection with SOFI, PALM, or RESOLFT. The choice of SRM technique depends on photoactivation, photoconversion, or photoswitching property of FP used in each study.

To enable super-resolution imaging of BiFC, fluorescent reporter moiety of the indicators is switched from a constitutive FP to a phototransformable one (Figure 1). From the view point of protein engineering, the main challenge is to experimentally identify split site for each phototransformable FP with hints from the protein structure. Importantly, FPs must regain both fluorescence and phototransformability after bimolecular complementation. To date, BiFC split sites have been reported for several phototransformable FPs including cpDMVF (a circular-permutated mutant of the reversibly 
photoswitchable FP Dronpa) [58], PAmCherry1 [59], mEos3.2 [60], PA-GFP [61], mIrisFP [62], and rsEGFP2 [63]. While only one split site was identified in most cases, two split sites at a.a. 150 and a.a. 165 were reported for mIrisFP, which enables the detection of three proteins forming a complex (Three-Fragment Fluorescence Complementation, i.e., TFFC, is an extension of the BiFC technology) [62]. For proof of concept, mIrisFP-based TFFC system was applied to the heterotrimer of $\mathrm{G}_{\mathrm{s}}$ protein which contains $\alpha_{s}, \beta_{1}$, and $\gamma_{2}$ subunits. In combination with PALM microscopy, signal-dependent dissociation of $\alpha_{\mathrm{S}}$ subunit from the $\beta_{1}$ and $\gamma_{2}$ heterodimer was revealed [62].

Despite the hassle of finding functional split sites for phototransformable FPs, the downstream super-resolution observation of PPIs is relatively straightforward. Sample preparation is identical to conventional $\mathrm{BiFC}$, and standard SRM methods are adopted without major modification to the imaging protocols. The technique branches into three categories based on the choice of SRM module: refSOFI (i.e., BiFC-SOFI) [58], BiFC-PALM [59-62], and BiFC-RESOLFT [63]. The main difference among these implementations is the particular combination of achievable spatial and temporal resolutions. For instance, localization precision of BiFC-PALM is as high as tens of nanometers, but acquisition of each PALM image can take up to minutes. refSOFI is faster because larger proportion of fluorophores stay in fluorescence-on state and smaller number of raw frames are required for reconstructing each SOFI image, but spatial resolution is around $100 \mathrm{~nm}$ and shies away from SMLM. Reported BiFC-based phototransformable indicators and their uses are summarized in Table 1. Nevertheless, BiFC-based indicators come with a few limitations. First, kinetics of these indicators is slow. There is a lag between interaction occurrence and the onset of detectable fluorescence, with chromophore maturation being the rate-limiting step. Depending on maturation speed of each $\mathrm{FP}$, the delay may range from several minutes to hours. Second, BiFC is mostly an irreversible process. After BiFC occurs, the associated status cannot be reverted. Although mostly a nuisance for observing dynamic dissociation and reassociation, the irreversibility does bring an unexpected benefit for SRM practice. Because the complemented status of indicator molecule is locked-in, transient PPIs that would otherwise escape real-time detection will leave behind a stable fluorescent signature. This make post-hoc detection possible and the use of SRM techniques of slow temporal resolution a practical option. Notably, as an alternative to the BiFC of $\beta$-barrel type FPs, splitFAST, a reversible split fluorescent reporter was developed recently based a phytochrome FP variant that binds a fluorogen [64]. The splitFAST system consists of two split fragments of a $14 \mathrm{kDa}$ photoactive yellow protein (PYP) mutant derived from Halorhodospira halophila, which recruit hydroxybenzylidene rhodanine (HBR) analogs as external chromophores after protein complementation. The FP-fluorogen complex is reversible and therefore overcomes one limitation of traditional BiFC for monitoring dynamic interactions.

\subsection{Diffraction-Unlimited Observation of Biomolecule Interactions by Points Accumulation for Imaging Nanoscale Topography (PAINT) with Photoconvertible Fluorescent Proteins}

The migration of BiFC-based PPI imaging from diffraction-limited to SRM feels more like an upgrade than a completely new invention. By breaking away from the standard indicator design philosophy and tapping into the fundamentals of single-molecule imaging, points accumulation for imaging nanoscale topography (PAINT) has been repurposed for imaging biomolecule interactions at super resolution (Table 1). To distinguish itself from PALM, PAINT relies on binding of fluorescent ligands to stationary targets, rather than stochastic photoactivation of permanently bound fluorophores to generate single-molecule blinking. In its original form, PAINT is performed with Nile Red dye which is transiently immobilized when colliding with the sample surface [65]. Later, specificity of PAINT in fixed cells was boosted by using complementary DNA strands to induce transient bindings (DNA-PAINT) [66]. For functional SRM of PPIs, the concept of PAINT has been generalized to the genetically encoded system of FPs. To illustrate the idea behind PAINT-based PPI detection, imagine a case of investigating the interaction between a diffusive protein $\mathrm{A}$ and stationary protein $\mathrm{B}$ (Figure 2). Here, protein A is fused to an FP, and protein B serves as the bait. In the absence of interaction, protein A molecule diffuses freely, and its image is motion-blurred and dim. Upon interacting, protein A 
docks to protein $\mathrm{B}$, and image of the transiently immobilized protein A now appears as a bright and sharp dot. With appropriate camera exposure, only the subpopulation of protein A molecules that interact with protein B assume a well-defined Gaussian PSF. Therefore, only interacting molecules are localizable and contribute to the reconstructed super-resolution image (Figure 2).

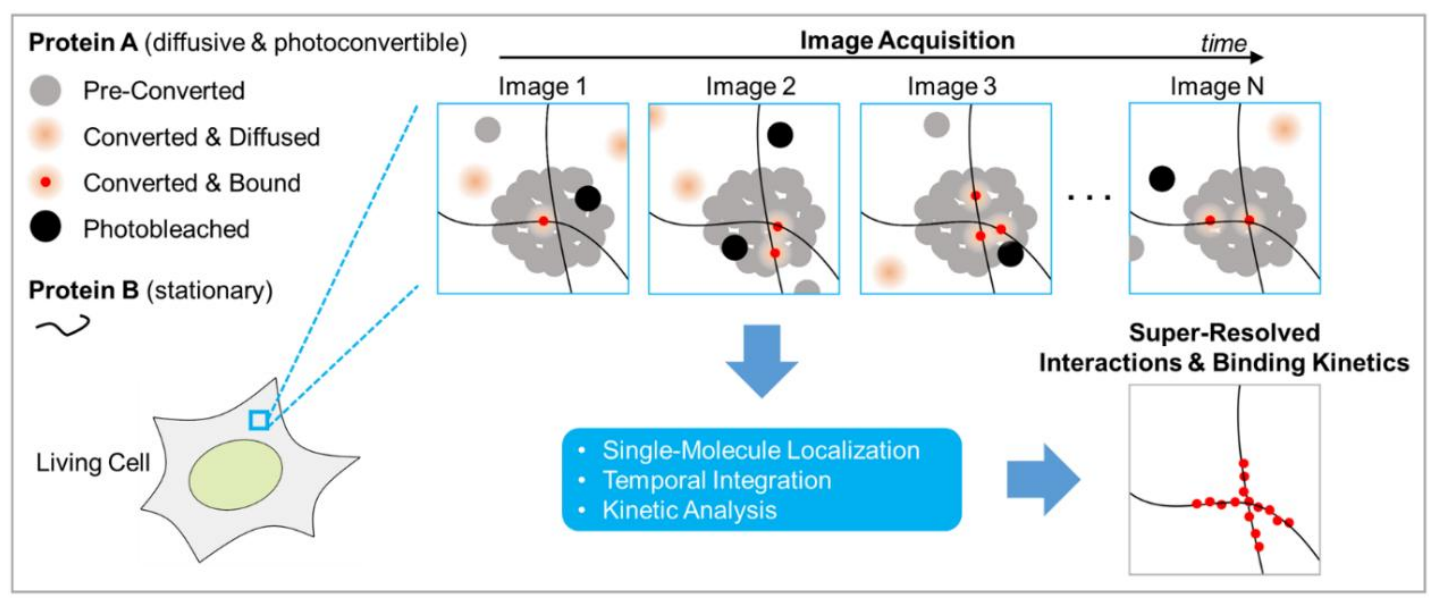

Figure 2. Principle of super-resolution imaging of biomolecule interactions with PAINT-PALM. For illustration purpose, the interactions between a diffusive protein A and a stationary protein B are shown here. The concept is readily generalizable to the imaging of protein-DNA or protein-RNA interactions in the nucleus, by replacing protein B with DNA or RNA in the figure. Here, the diffusive protein A is fused to a photoconvertible fluorescent protein (FP) and expressed in living cells. During experiment, the chimeric protein A (ligand) is stochastically photoconverted to fluoresces. On camera, the images of unbound protein A molecules appear motion-blurred because of diffusion. The images of protein A molecules interacting with protein B appear as sharp spots with well-defined Gaussian PSF, after transient immobilization. The interactions are sampled over time by acquiring an image sequence (image $1,2,3, \ldots, N)$. Super-resolved interaction map is generated by single-molecule localization and temporal integration. The temporal image sequence may also be subjected to additional analysis such as tcPALM to extract information on binding kinetics.

For example, plasma membrane binding of cytosolic proteins that are involved in the epidermal growth factor (EGF) signaling pathway was investigated with this approach. A photoconvertible FP mEOS3.2 was fused to Grb2, c-Raf, or PLC $\gamma 1$, respectively, and used as PAINT probes for membrane anchorage [67]. By combining PAINT with the green-to-red photoconversion of mEOS3.2 (PAINT-PALM), single-molecule imaging unraveled a membrane heterogeneity during spatiotemporal regulation of EGF signaling. Beyond PPI detection, this method was also applied to protein-DNA interaction and protein-RNA interaction in the nucleus. With a photoconvertible FP mEOS3.1, DNA binding of a replication licensing factor, $\mathrm{Mcm} 4$, and a processivity factor for DNA polymerase $\delta$, PCNA, were imaged at various stages of the cell cycle in living fission yeast [68]. For protein-DNA interaction in living mouse embryonic stem cells, the transcriptional factor Sox 2 was fluorescently labeled with TMR dye via HaloTag. And association kinetics of Sox 2 with chromatin was interrogated. Although in this study, TMR dye was the fluorescent ligand of HaloTag and the system was only partially genetically encoded [69]. For protein-RNA interaction, RNA polymerase II (Pol II) was labeled with Dendra2, an FP that converts from green to red emission upon UV illumination. Following PAINT, temporal clustering of Pol II in living mouse embryonic fibroblasts was quantified by time-correlated PALM (tcPALM). tcPALM is novel method for analyzing binding kinetics at super-resolution, and it was used here to estimate relative local concentrations of interacting protein from changes in the frequency of single-molecule detections [70,71].

Compared to the irreversibility of BiFC, diffusive PAINT probes are constantly replenished from the surrounding environment. This means that transient interactions can be sampled repeatedly, 
despite the fact that probes are irreversibly photoconverted or photobleached. Again, compared to $\mathrm{BiFC}$, which must wait for chromophore maturation, kinetics of PAINT imaging is fast. The real-time detection takes only tens to hundreds of milliseconds, which allow highly transient interaction to be monitored. Notably, phototransformation is not strictly required for PAINT-based functional SRM, providing interactions are already rare by nature and appear sparsely in snapshots (fewer than one fluorescent molecule per diffraction-limited volume). In practice, association affinity is high for many biomolecule interactions under physiological condition, which leads to densely populated fluorescence signals and low $\mathrm{S} / \mathrm{N}$. The introduction of photoconversion to PAINT, i.e., PAINT-PALM, helps break this concentration barrier by suppressing the density of on-state fluorophore and therefore allows for burst of interactions with high affinities to be super-resolved [72]. Further down the road, it might be possible to incorporate the concept of single-molecule photoactivation FRET (sm-PAFRET) to improve the range of detectable concentration with PAINT-based super-resolution interaction imaging [73].

Before moving on, a note should be taken for estimating spatial resolution in functional SRM. For single-molecule imaging such as PAINT-PALM and BiFC-PALM, localization precision is often reported (Table 1). Localization precision, i.e., optical resolution of the imaging system, only reflects how accurate the instrument can determine the position of single molecules. For conventional SRM that aims at resolving ultrafine structural features of, e.g., filaments and focal adhesions, localization precision alone can be insufficient and misleading for describing the revolving power [74,75]. Instead, structural resolution should also be measured by full width at half maximum (FWHM) or Fourier ring correlation (FRC) [76], etc. For functional SRM of PPIs, however, the precise locations of interactions and binding kinetics are arguably more informative than pure structural information. Thus the choice of reporting localization precision as the performance indicator of spatial resolution is somewhat justified in these cases of functional SRM. 
Table 1. Reported functional SRM studies of biomolecule interactions and biochemical activities in living cells with genetically encoded indicators.

\begin{tabular}{|c|c|c|c|c|c|c|c|c|c|c|c|c|c|}
\hline Application & Name & Target & Class & FP & $\begin{array}{c}\text { FP } \\
\text { Config. }\end{array}$ & Split Site(s) & Microscopy & $\begin{array}{c}\text { Localization } \\
\text { Precision }^{1}\end{array}$ & FWHM $^{2}$ & Kinetics & Reversibility & $\begin{array}{c}\text { Cell } \\
\text { Type(s) }\end{array}$ & Ref. \\
\hline $\begin{array}{l}\text { Rapamycin-induced FKBP and } \\
\text { FRB interaction }\end{array}$ & refSOFI & $\begin{array}{l}\text { Protein-protein } \\
\text { interaction }\end{array}$ & $\mathrm{BiFC}$ & DMVF & cp; split & a.a. 181 & SOFI & N/A & $\sim 100 \mathrm{~nm}$ & Slow $^{3}$ & No & HeLa & [58] \\
\hline $\begin{array}{l}\text { Interaction of receptor tyrosine } \\
\text { kinases HER2 \& } 3\end{array}$ & refSOFI & $\begin{array}{c}\text { Protein-protein } \\
\text { interaction }\end{array}$ & $\mathrm{BiFC}$ & DMVF & cp; split & a.a. 181 & SOFI & N/A & $\sim 100 \mathrm{~nm}$ & Slow $^{3}$ & No & HeLa & [58] \\
\hline $\begin{array}{l}\text { Interaction of ER } \mathrm{Ca}^{2+} \text { sensor } \\
\text { STIM1 and } \mathrm{Ca}^{2+} \text { channel protein } \\
\text { ORAI1 }\end{array}$ & refSOFI & $\begin{array}{l}\text { Protein-protein } \\
\text { interaction }\end{array}$ & $\mathrm{BiFC}$ & DMVF & cp; split & a.a. 181 & SOFI & N/A & $\sim 100 \mathrm{~nm}$ & Slow $^{3}$ & No & HeLa & [58] \\
\hline $\begin{array}{l}\text { Interactions of small GTPase Ras } \\
\text { and its effector Raf }\end{array}$ & BiFC-PALM & $\begin{array}{c}\text { Protein-protein } \\
\text { interaction }\end{array}$ & $\mathrm{BiFC}$ & PA-mCherry 1 & y1 split & a.a. 159 & PALM & $18 \mathrm{~nm}$ & N/A & Slow $^{3}$ & No & $\mathrm{U} 2 \mathrm{OS}$ & [59] \\
\hline Interaction of MreB and EF-Tu & BiFC-PALM & $\begin{array}{l}\text { Protein-protein } \\
\text { interaction }\end{array}$ & $\mathrm{BiFC}$ & mEos3.2 & split & a.a. 164 & PALM & $12 \mathrm{~nm}$ & $\mathrm{~N} / \mathrm{A}$ & Slow $^{3}$ & No & E. coli & [60] \\
\hline $\begin{array}{c}\text { Homodimerization of } \\
\text { microtubule plus-end hub } \\
\text { protein EB1 }\end{array}$ & BiFC-PALM & $\begin{array}{l}\text { Protein-protein } \\
\text { interaction }\end{array}$ & $\mathrm{BiFC}$ & PA-GFP & split & not specified & PALM & $23 \mathrm{~nm}$ & $\mathrm{~N} / \mathrm{A}$ & Slow $^{3}$ & No & $\begin{array}{l}\text { HeLa; } \\
\text { MCF7 }\end{array}$ & [61] \\
\hline $\begin{array}{c}\text { Formation of bJun/bFos } \\
\text { complexes }\end{array}$ & BiFC-PALM & $\begin{array}{c}\text { Protein-protein } \\
\text { interaction }\end{array}$ & BiFC & mIrisFP & split & a.a. 150 ; a.a. 165 & PALM & $18 \mathrm{~nm}$ & N/A & Slow $^{3}$ & No & Vero cells & [62] \\
\hline $\begin{array}{l}\text { Interaction among } \alpha_{\mathrm{s}}, \beta_{1} \text {, and } \gamma_{2} \\
\text { subunits of } G_{s} \text { ternary complex }\end{array}$ & TFFC-PALM & $\begin{array}{l}\text { Protein-protein } \\
\text { interaction }\end{array}$ & $\mathrm{TFFC}^{4}$ & mIrisFP & split & a.a. $150 \&$ a.a. 165 & PALM & $18 \mathrm{~nm}$ & N/A & Slow $^{3}$ & No & Vero cells & [62] \\
\hline Interaction of Bcl-xL and Bak & BiFC-RESOLFT & $\begin{array}{l}\text { Protein-protein } \\
\text { interaction }\end{array}$ & $\mathrm{BiFC}$ & rsEGFP2 & split & a.a. 158 & RESOLFT & N/A & $113 \mathrm{~nm}$ & Slow $^{3}$ & No & Hela & [63] \\
\hline $\begin{array}{l}\text { Membrane-binding of proteins in } \\
\text { EGF signaling pathway }\end{array}$ & PAINT-PALM & $\begin{array}{c}\text { Proteinprotein } \\
\text { interaction }\end{array}$ & PAINT & mEos3.2 & default & N/A & PALM & $35 \mathrm{~nm}$ & N/A & fast & Yes $^{5}$ & $\begin{array}{l}\text { HeLa; } \\
\text { CHO }\end{array}$ & [67] \\
\hline $\begin{array}{l}\text { Binding of PCNA and Mcm } 4 \\
\text { proteins to genomic DNA }\end{array}$ & PAINT-PALM & $\begin{array}{c}\text { Protein-DNA } \\
\text { interaction }\end{array}$ & PAINT & mEos3.1 & default & $\mathrm{N} / \mathrm{A}$ & PALM & $11 \mathrm{~nm}$ & N/A & fast & Yes $^{5}$ & $\begin{array}{c}\text { fission } \\
\text { yeast }\end{array}$ & [68] \\
\hline $\begin{array}{c}\text { Dynamics of RNA Pol II } \\
\text { clustering at } \beta \text {-actin gene locus }\end{array}$ & PAINT-PALM & $\begin{array}{l}\text { Protein-RNA } \\
\text { interaction }\end{array}$ & PAINT & Dendra2 & default & N/A & PALM & $31 \mathrm{~nm}$ & $\mathrm{~N} / \mathrm{A}$ & fast & Yes $^{5}$ & MEF & [71] \\
\hline Protein Kinase A (PKA) activity & FLINC-AKAR1 & $\begin{array}{c}\text { Biochemical } \\
\text { activity }\end{array}$ & FLINC & TagRFP-T & default & $\mathrm{N} / \mathrm{A}$ & SOFI & N/A & $\begin{array}{c}107-179 \\
\mathrm{~nm}\end{array}$ & fast & Yes & $\begin{array}{l}\text { HeLa; } \\
\alpha 4 \mathrm{CHO}\end{array}$ & [77] \\
\hline $\begin{array}{l}\text { Extracellular signal-regulated } \\
\text { kinase (ERK) activity }\end{array}$ & FLINC-EKAR1 & $\begin{array}{l}\text { Biochemical } \\
\text { activity }\end{array}$ & FLINC & TagRFP-T & default & $\mathrm{N} / \mathrm{A}$ & SOFI & N/A & $160 \mathrm{~nm}$ & fast & Yes & HEK293 & [77] \\
\hline $\begin{array}{l}\text { Rapamycin-induced FKBP and } \\
\text { FRB interaction }\end{array}$ & $\begin{array}{l}\text { bimolecular } \\
\text { FLINC }\end{array}$ & $\begin{array}{l}\text { Protein-protein } \\
\text { interaction }\end{array}$ & FLINC & TagRFP-T & default & N/A & SOFI & N/A & $\begin{array}{l}\sim 107-160 \\
\mathrm{~nm}\end{array}$ & fast & Yes & HeLa & [77] \\
\hline $\begin{array}{l}\text { Interaction of FHA1 and PKA } \\
\text { phosphosubstrate }\end{array}$ & $\begin{array}{l}\text { bimolecular } \\
\text { FLINC-AKAR1 }\end{array}$ & $\begin{array}{l}\text { Protein-protein } \\
\text { interaction }\end{array}$ & FLINC & TagRFP-T & default & N/A & SOFI & N/A & $\begin{array}{c}\sim 107-160 \\
\mathrm{~nm}\end{array}$ & fast & Yes & HeLa & [77] \\
\hline
\end{tabular}

hosphosubstrate

$\begin{array}{lrl}\text { bimolecular } & \text { Protein-protein } \\ \text { FLINC-AKAR1 } & \text { interaction }\end{array}$

${ }^{1}$ Localization Precision is a parameter to report optic resolution in single-molecule localization microscopy. ${ }^{2}$ Full width at half maximum (FWHM) is a parameter to report structura resolution in microscopy. Separation of structural features, i.e., intensity peak-to-peak distance, is also used to report structural resolution in a few cases in Table $1 .{ }^{3}$ The onset of fluorescence in BiFC and TFFC systems are rate limited by maturation speed of the chromophore. ${ }^{4}$ Three-fragment fluorescence complementation (TFFC) is a variant of BiFC for detecting interactions among three protein components. ${ }^{5}$ Although photoconversion of the FPs from green to red emission is irreversible, new pre-converted probes are replenished from the surrounding environment thus enable de novo binding to target molecules. a.a.: amino acid; N/A: not applicable. 
3.3. Diffraction-Unlimited Observation of Biomolecular Activities Based on Fluorescence Fluctuation Increase by Contact (FLINC)

While biomolecule interactions including PPIs, protein-DNA interactions, and protein-RNA interactions can be super-resolved with BiFC-type or PAINT-type indicators, diffraction-unlimited observation of biochemical activities has been elusive until very recently. As an unconventional phototransformation phenomenon, fluorescence fluctuation increase by contact (FLINC) broke this silence by using fluorophore blinking behavior as a quantitative readout [77]. FLINC is the unexpected discovery of fluorescence fluctuations of TagRFP-T in physical approximation to Dronpa, a reversely photoswitchable FP. TagRFP-T is generally considered a constitutive FP lacking obvious photoactivation, photoswitching, or photoconversion behavior. However, TagRFP-T displays elevated degree of fluctuations as its distance to Dronpa shortens. Because the extent of fluctuations can be quantified at subpixel level on SOFI image with high-order cumulant statistics, indicators that convert biochemical activities to distance change between TagRFP-T and Dronpa were developed. To this end, a FLINC-AKAR1 indicator for protein kinase A (PKA) activity was made first for proof of concept. PKA dynamics was monitored with nanometer precision on intensity-normalized SOFI images, i.e., activity maps. Apart from detecting biochemical activities, FLINC was also generalized for the detection of PPI (Table 1). By fusing TagRFP-T and Dronpa to each interacting component, respectively, an intermolecular FLINC system was developed for rapamycin-inducible dimerization between the FK506-binding protein (FKBP) and FKBP-rapamycin binding domain (FRB). Following a similar strategy, a bimolecular version of FLINC-AKAR1 was also developed by splitting the indicator into two components-FHA1-Dronpa and PKA-substrate-TagRFP-T_-for detecting the weak interaction between FHA1 and phosphosubstrate.

It is noteworthy that FLINC is independent of either Dronpa emission or photoswitching, as demonstrated by TagRFP-T fluctuations inflicted by a non-fluorescent Dronpa mutant [77]. In that sense, the mechanism of FLINC is unique and probably akin to Dronpa-assisted disturbance to the local chromophore environment of TagRFP-T. Before a complete mechanistic understanding is drawn, it is challenging to rationally design new FLINC pairs other than the TagRFP-T-Dronpa duo. Regardless, it will be exciting to see other indicators that exploit unexpected photophysics of FPs in the future. As a note of summary, the barriers of entry or accessibility of BiFC, PAINT and FLINC indicators for functional SRM are compared in Figure 3.

\section{Through the Looking Glass: Exploiting Phototransformation of Fluorescent Proteins for Improved Bioimaging and Biomolecular Sensing}

It is perhaps apparent by now that FP phototransformation can turn out to be a valuable trait for bioimaging [55]. In fact, weak on and off blinking of GFP was documented at least two decades ago [78]. For a long time, blinking was treated as a nuisance, for it leads to unstable signals in ensemble imaging. That is until SRM finally leveraged upon it and revolutionized fluorescence imaging. Since then, FPs have been actively engineered to introduce favorable phototransformation properties such as faster photoswitching speed and high on/off contrast.

Apart from being the cornerstone of many SRM techniques, phototransformation also brings extra benefits to fluorescence imaging and opens up new possibilities for indicator engineering. To reduce photodamage in STED microscopy, RESOLFT swaps constitutive FPs for reversely photoswitchable ones and achieves sizable reduction in depletion laser power [79]. The end result is higher biocompatibility for cell and in vivo imaging. In the same fashion, phototoxicity may also be suppressed by using photoswitching FPs in other SRM techniques that involves STED beam, e.g., the use of a reversely photoswitchable FP, Kohinoor, in SPoD-ExPAN microscopy dramatically reduced the illumination laser power from $1.7 \mathrm{MW} / \mathrm{cm}^{2}$ to $\sim 1 \mathrm{~W} / \mathrm{cm}^{2}[80,81]$. 


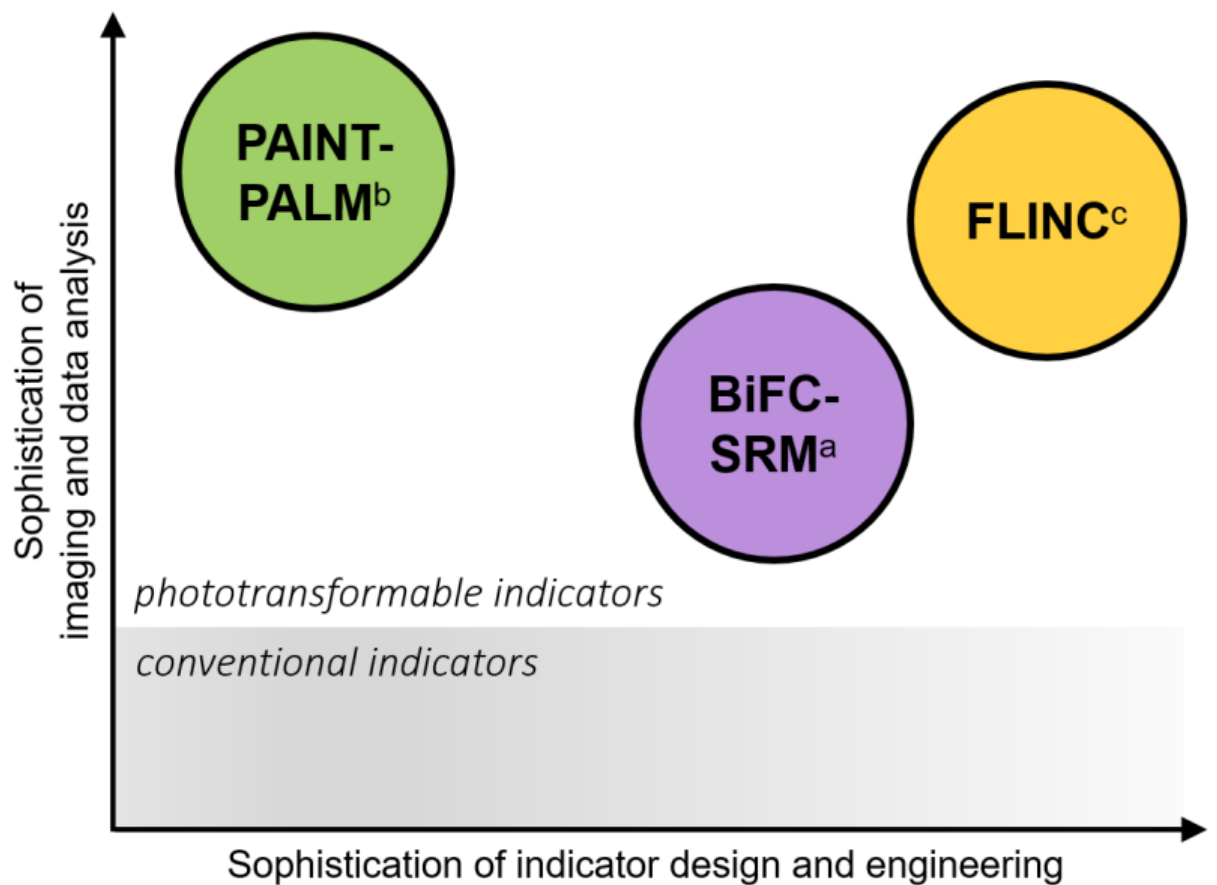

Figure 3. Accessibility of genetically encoded indicators derived from phototransformable fluorescent proteins for functional super-resolution imaging. a: BiFC-based indicators for SRM (BiFC-SRM) borrow the design basics from conventional BiFC indicators. The main challenges for engineering these indicators are two-folds: The first is to identify split site(s) that permits reconstitution of fluorescence and phototransformation; The second is fast chromophore maturation after complementation. Methods for SRM are straightforwardly adopted from SOFI, PALM, or RESOLFT with little modification. b: PAINT-PALM indicators are simply engineered by fusing a phototransformable FP to the diffusive protein of interest. For SRM of biomolecule interactions, both camera exposure and single-molecule localization algorithm must be fine-tuned. The goal is to filter out unbound and motion-blurred emitters (fail if exposure is too short and inclusion criteria set too low); in the meantime, bound emitters must assume well-defined Gaussian PSFs to be successfully localized (fail if exposure is too long and inclusion criteria set too high). c: Design of FLINC indicator is generalizable to the detection of both biochemical activities and PPI. Main limitation is the incomplete mechanistic understanding of FLINC phenomenon, which limits the discovery of new FLINC protein pairs. To generate super-revolved map of biomolecular activities, cumulant values must be properly normalized to eliminate bias from uneven distribution of indicators across the cell.

Another example of photodamage reduction is found in photoswitching FRET (psFRET) [82]. Compared to the traditional photobleaching FRET that measures donor photobleaching kinetics (not to be confused with acceptor photobleaching), psFRET uses a reversely photoswitchable FP as donor and infers FRET efficiency from photoswitching speed or fluorescence lifetime. Because acceptor absorption introduces an alternative energy transfer pathway that competes with photoswitching, slower switching off kinetics of the donor and longer lifetime are expected when FRET occurs. Here, photochromism not only leads to less aggressive illumination, but also make FRET measurement reversible since donor is temporally turn off, rather than permanently bleached out. For proof of concept, a FRET pair of Dronpa and mCherry was established. Widefield psFRET imaging of PPI and biochemical activity were demonstrated respectively with the observation of histone $2 \mathrm{~B}$ compaction and a caspase indicator [82].

For developing single-FP indicators, an ambitious concept is to directly encode information of biomolecular activities within phototransformation. Remarkably, a unique single-FP $\mathrm{Ca}^{2+}$ indicator named CaMPARI was reported recently, in which photoconversion of mEOS2 is driven by the binding of calcium ions to calmodulin [83]. mEOS2 is a photoconvertible FP that switches emission from green 
to red under UV illumination [84]. From the template of $\mathrm{Ca}^{2+}$ indicator GCaMP, the fluorescent reporter cpEGFP is replaced by circularly permutated mEOS2, followed by mutagenesis-based molecular evolution. The result is a molecular switch that couples photoconversion to $\mathrm{Ca}^{2+}$ concentration. During calcium imaging, CaMPARI is first potentiated by UV light. The indicator changes emission color from green to red in proportion to $\mathrm{Ca}^{2+}$ concentration. Because photoconversion of mEOS2 is irreversible, the red/green emission ratio keeps a permanent record of total calcium flux during UV illumination. Meanwhile, $\mathrm{S} / \mathrm{N}$ is also boosted by the integration of fluorescence signals over time. Therefore, CaMPARI is advantageous for recording weak and transient $\mathrm{Ca}^{2+}$ flux and has been applied to calcium imaging in neuronal system $[83,85]$.

Finally, performance of phototransformable FPs can be improved without introducing extra mutations to their protein sequences. This is usually achieved through a fusion partner that modulates fluorescence properties of the FPs. For example, photostability of a photoconvertible FP, mEOS3.2, was increased two-fold, after the ligation of Janelia Fluor $646\left(\mathrm{JF}_{646}\right)$ dye via a HaloTag [86]. JF 646 quenched the photoconverted population of mEOS3.2 by FRET and therefore competed with photobleaching pathway of the FP. As a result, the FRET-assisted mEOS3.2 stayed longer in the red emission state, thus allowed particle tracking at single-molecule level for extended periods of time [86]. In another instance, a camelid-derived single-domain antibody, i.e., nanobody, was fused to a reversely photoswitchable FP, rsGreens [87], to enhance its molecular brightness, pH stability, and switching property [88]. Nanobody fusion has been previously documented to modulate the chromophore environment of GFP family FPs [89]. Dimerization, i.e., the intermolecular binding between GFP and nanobody, was implied as a mechanism for the enhanced FP properties [90].

\section{Conclusions and Perspectives}

We are witnessing a coming of age of the discipline of genetically encoded indicators, as designs of indicators begin to consolidate for applications that evoke ensemble imaging. Historically, it was the invention of FP toolbox that propelled the field to its current flourishing state. It is encouraging to anticipate that phototransformable FPs could lay the foundation for a renaissance with functional SRM. Indeed, the young field has recently begun to gain its momentum, and many inspirations can be drawn from the success of super-resolution BiFC, PAINT, and FLINC indicators. On the flip side, there are also lessons to be learnt. While conventional microscopy is ubiquitous and relatively intuitive, SRM and its image analysis pipeline remain daunting for biologists without training in optics and programming. This gap is perhaps growing wider without active dialogues and the sharing of vocabularies between microscopists and protein engineers. On the other hand, the photochemistry behind light-induced FP transformation remains to be fully understood. Without that piece of the puzzle, the rational design of new indicators is largely stalled, as exemplified by the rarity of indicators like FLINC. In summary, the functional SRM of biomolecular activities is rapidly becoming a highly interdisciplinary topic. A joint force of FP engineers, indicator developers, microscopists and programmers is expected to improve this technology for seeing the minuscule and fleeting singularities in the cellular clockwork.

Funding: This work was partly supported by the "JST-CREST" (No. JPMJCR15N3) and the MEXT 'Grant-in-Aid for Scientific Research on Innovative Areas' 'Singularity Biology' (No. 18H05410) to T.N.

Acknowledgments: The authors thank Richard Gordon for proofreading the manuscript.

Conflicts of Interest: The authors declare no conflict of interest. The funders had no role in the design of the study; in the collection, analyses, or interpretation of data; in the writing of the manuscript, or in the decision to publish the results. 


\section{Abbreviations}

\begin{tabular}{|c|c|}
\hline a.a. & amino acid \\
\hline $3 B$ & Bayesian analysis of the blinking and bleaching \\
\hline BiFC & bimolecular fluorescence complementation \\
\hline $\mathrm{cp}$ & circular permutation \\
\hline CRISPR & clustered regularly interspaced short palindromic repeats \\
\hline EGF & epidermal growth factor \\
\hline ESI & entropy-based super-resolution imaging \\
\hline FKBP & FK506-binding protein \\
\hline FLINC & fluorescence fluctuation increase by contact \\
\hline FP & fluorescent protein \\
\hline FRB & FKBP-rapamycin binding domain \\
\hline FRC & Fourier ring correlation \\
\hline FRET & Förster resonance energy transfer \\
\hline FWHM & full width at half maximum \\
\hline GFP & Aequorea Victoria green fluorescence protein \\
\hline HBR & hydroxybenzylidene rhodanine \\
\hline HILO & highly inclined and laminated optical sheet \\
\hline $\mathrm{JF}_{646}$ & Janelia Fluor 646 \\
\hline MUSICAL & multiple signal classification algorithm \\
\hline $\mathrm{N} / \mathrm{A}$ & not applicable \\
\hline PAINT & points accumulation for imaging nanoscale topography \\
\hline PALM & photo-activated localization microscopy \\
\hline PKA & protein kinase $\mathrm{A}$ \\
\hline Pol II & RNA polymerase II \\
\hline PPI & Protein-protein interaction \\
\hline PSF & point spread function \\
\hline psFRET & photoswitching FRET \\
\hline ptFP & phototransformable fluorescent protein \\
\hline PYP & photoactive yellow protein \\
\hline RESOLFT & reversible saturable optical fluorescence transitions \\
\hline $\mathrm{S} / \mathrm{N}$ & signal-to-noise ratio \\
\hline SCORE & spatial covariance reconstructive \\
\hline SIM & structured illumination microscopy \\
\hline sm-FRET & single-molecule photoactivation FRET \\
\hline SMLM & single-molecule localization microscopy \\
\hline SOFI & super-resolution optical fluctuation imaging \\
\hline SRM & super-resolution light microscopy \\
\hline SRRF & super-resolution radial fluctuations \\
\hline STED & stimulated emission depletion \\
\hline TALEN & transcription activator-like effector nucleases \\
\hline tcPALM & time-correlated photo-activated localization microscopy \\
\hline TFFC & three-fragment fluorescence complementation \\
\hline TIRF & total internal reflection fluorescence \\
\hline Tet & tetracycline \\
\hline UV & ultraviolet \\
\hline
\end{tabular}

\section{References}

1. Bogdanov, A.M.; Mishin, A.S.; Yampolsky, I.V.; Belousov, V.V.; Chudakov, D.M.; Subach, F.V.; Verkhusha, V.V.; Lukyanov, S.; Lukyanov, K.A. Green fluorescent proteins are light-induced electron donors. Nat. Chem. Biol. 2009, 5, 459-461. [CrossRef]

2. Tsien, R.Y. The green fluorescent protein. Annu. Rev. Biochem. 1998, 67, 509-544. [CrossRef] 
3. Prendergast, F.G.; Mann, K.G. Chemical and physical properties of aequorin and the green fluorescent protein isolated from Aequorea forskalea. Biochemistry 1978, 17, 3448-3453. [CrossRef]

4. Duwé, S.; Dedecker, P. Optimizing the fluorescent protein toolbox and its use. Curr. Opin. Biotechnol. 2019, 58, 183-191. [CrossRef]

5. Xue, L.; Karpenko, I.A.; Hiblot, J.; Johnsson, K. Imaging and manipulating proteins in live cells through covalent labeling. Nat. Chem. Biol. 2015, 11, 917-923. [CrossRef] [PubMed]

6. Miyawaki, A.; Llopis, J.; Heim, R.; McCaffery, J.M.; Adams, J.A.; Ikura, M.; Tsien, R.Y. Fluorescent indicators for $\mathrm{Ca} 2+$ based on green fluorescent proteins and calmodulin. Nature 1997, 388, 882-887. [CrossRef] [PubMed]

7. Newman, R.H.; Fosbrink, M.D.; Zhang, J. Genetically encodable fluorescent biosensors for tracking signaling dynamics in living cells. Chem. Rev. 2011, 111, 3614-3666. [CrossRef] [PubMed]

8. Greenwald, E.C.; Mehta, S.; Zhang, J. Genetically encoded fluorescent biosensors illuminate the spatiotemporal regulation of signaling networks. Chem. Rev. 2018, 118, 11707-11794. [CrossRef]

9. Abbe, E. Beiträge zur Theorie des Mikroskops und der mikroskopischen Wahrnehmung. Arch. Mikrosk. Anat. 1873, 9, 413-468. [CrossRef]

10. Yan, R.; Wang, B.; Xu, K. Functional super-resolution microscopy of the cell. Curr. Opin. Chem. Biol. 2019, 51, 92-97. [CrossRef]

11. Gould, T.J.; Gunewardene, M.S.; Gudheti, M.V.; Verkhusha, V.V.; Yin, S.R.; Gosse, J.A.; Hess, S.T. Nanoscale imaging of molecular positions and anisotropies. Nat. Methods 2008, 5, 1027-1030. [CrossRef] [PubMed]

12. Cruz, C.A.V.; Shaban, H.A.; Kress, A.; Bertaux, N.; Monneret, S.; Mavrakis, M.; Savatier, J.; Brasselet, S. Quantitative nanoscale imaging of orientational order in biological filaments by polarized superresolution microscopy. Proc. Natl. Acad. Sci. USA 2016, 113, E820-E828. [CrossRef] [PubMed]

13. Sezgin, E.; Schneider, F.; Zilles, V.; Urbančič, I.; Garcia, E.; Waithe, D.; Klymchenko, A.S.; Eggeling, C. Polarity-sensitive probes for superresolution stimulated emission depletion microscopy. Biophys. J. 2017, 113, 1321-1330. [CrossRef] [PubMed]

14. Bongiovanni, M.N.; Godet, J.; Horrocks, M.H.; Tosatto, L.; Carr, A.R.; Wirthensohn, D.C.; Ranasinghe, R.T.; Lee, J.-E.; Ponjavic, A.; Fritz, J.V.; et al. Multi-dimensional super-resolution imaging enables surface hydrophobicity mapping. Nat. Commun. 2016, 7, 13544. [CrossRef]

15. Horikawa, K.; Yamada, Y.; Matsuda, T.; Kobayashi, K.; Hashimoto, M.; Matsu-ura, T.; Miyawaki, A.; Michikawa, T.; Mikoshiba, K.; Nagai, T. Spontaneous network activity visualized by ultrasensitive Ca ${ }^{2+}$ indicators, yellow Cameleon-Nano. Nat. Methods 2010, 7, 729-732. [CrossRef]

16. Farhana, I.; Hossain, M.N.; Suzuki, K.; Matsuda, T.; Nagai, T. Genetically encoded fluorescence/ bioluminescence bimodal indicators for $\mathrm{Ca}^{2+}$ imaging. ACS Sens. 2019, 4, 1825-1834. [CrossRef]

17. Nagai, T.; Sawano, A.; Park, E.S.; Miyawaki, A. Circularly permuted green fluorescent proteins engineered to sense $\mathrm{Ca}^{2+}$. Proc. Natl. Acad. Sci. USA 2001, 98, 3197-3202. [CrossRef]

18. Cabantous, S.; Terwilliger, T.C.; Waldo, G.S. Protein tagging and detection with engineered self-assembling fragments of green fluorescent protein. Nat. Biotechnol. 2005, 23, 102-107. [CrossRef]

19. Romoser, V.A.; Hinkle, P.M.; Persechini, A. Detection in living cells of $\mathrm{Ca}^{2+}$-dependent changes in the fluorescence emission of an indicator composed of two green fluorescent protein variants linked by a calmodulin-binding sequence. A new class of fluorescent indicators. J. Biol. Chem. 1997, 272, 13270-13274. [CrossRef]

20. Griesbeck, O.; Baird, G.S.; Campbell, R.E.; Zacharias, D.A.; Tsien, R.Y. Reducing the environmental sensitivity of yellow fluorescent protein. Mechanism and applications. J. Biol. Chem. 2001, 276, 29188-29194. [CrossRef]

21. Wachter, R.M.; Elsliger, M.A.; Kallio, K.; Hanson, G.T.; Remington, S.J. Structural basis of spectral shifts in the yellow-emission variants of green fluorescent protein. Structure 1998, 6, 1267-1277. [CrossRef]

22. Tojima, T.; Akiyama, H.; Itofusa, R.; Li, Y.; Katayama, H.; Miyawaki, A.; Kamiguchi, H. Attractive axon guidance involves asymmetric membrane transport and exocytosis in the growth cone. Nat. Neurosci. 2007, 10, 58-66. [CrossRef] [PubMed]

23. Klar, T.A.; Hell, S.W. Subdiffraction resolution in far-field fluorescence microscopy. Opt. Lett. 1999, 24, 954-956. [CrossRef] [PubMed]

24. Stephan, T.; Roesch, A.; Riedel, D.; Jakobs, S. Live-cell STED nanoscopy of mitochondrial cristae. Sci. Rep. 2019, 9, 12419. [CrossRef] 
25. Kamper, M.; Ta, H.; Jensen, N.A.; Hell, S.W.; Jakobs, S. Near-infrared STED nanoscopy with an engineered bacterial phytochrome. Nat. Commun. 2018, 9, 4762. [CrossRef]

26. Mishina, N.M.; Mishin, A.S.; Belyaev, Y.; Bogdanova, E.A.; Lukyanov, S.; Schultz, C.; Belousov, V.V. Live-cell STED microscopy with genetically encoded biosensor. Nano Lett. 2015, 15, 2928-2932. [CrossRef]

27. Boudreau, C.; Wee, T.L.; Duh, Y.R.; Couto, M.P.; Ardakani, K.H.; Brown, C.M. Excitation light dose engineering to reduce photo-bleaching and photo-toxicity. Sci. Rep. 2016, 6, 30892. [CrossRef]

28. Wäldchen, S.; Lehmann, J.; Klein, T.; van de Linde, S.; Sauer, M. Light-induced cell damage in live-cell super-resolution microscopy. Sci. Rep. 2015, 5, 15348. [CrossRef]

29. Oliinyk, O.S.; Shemetov, A.A.; Pletnev, S.; Shcherbakova, D.M.; Verkhusha, V.V. Smallest near-infrared fluorescent protein evolved from cyanobacteriochrome as versatile tag for spectral multiplexing. Nat. Commun. 2019, 10, 279. [CrossRef]

30. Shcherbakova, D.M.; Baloban, M.; Emelyanov, A.V.; Brenowitz, M.; Guo, P.; Verkhusha, V.V. Bright monomeric near-infrared fluorescent proteins as tags and biosensors for multiscale imaging. Nat. Commun. 2016, 7, 12405. [CrossRef]

31. Rodriguez, E.A.; Tran, G.N.; Gross, L.A.; Crisp, J.L.; Shu, X.; Lin, J.Y.; Tsien, R.Y. A far-red fluorescent protein evolved from a cyanobacterial phycobiliprotein. Nat. Methods 2016, 13, 763-769. [CrossRef] [PubMed]

32. Guerra, J.M. Super-resolution through illumination by diffraction-born evanescent waves. Appl. Phys. Lett. 1995, 66, 3555-3557. [CrossRef]

33. Hess, S.T.; Girirajan, T.P.K.; Mason, M.D. Ultra-high resolution imaging by fluorescence photoactivation localization microscopy. Biophys. J. 2006, 91, 4258-4272. [CrossRef] [PubMed]

34. Betzig, E.; Patterson, G.H.; Sougrat, R.; Lindwasser, O.W.; Olenych, S.; Bonifacino, J.S.; Davidson, M.W.; Lippincott-Schwartz, J.; Hess, H.F. Imaging intracellular fluorescent proteins at nanometer resolution. Science 2006, 313, 1642-1645. [CrossRef] [PubMed]

35. Dedecker, P.; Mo, G.C.H.; Dertinger, T.; Zhang, J. Widely accessible method for superresolution fluorescence imaging of living systems. Proc. Natl. Acad. Sci. USA 2012, 109, 10909-10914. [CrossRef] [PubMed]

36. Gustafsson, N.; Culley, S.; Ashdown, G.; Owen, D.M.; Pereira, P.M.; Henriques, R. Fast live-cell conventional fluorophore nanoscopy with ImageJ through super-resolution radial fluctuations. Nat. Commun. 2016, 7, 12471. [CrossRef]

37. Cox, S.; Rosten, E.; Monypenny, J.; Jovanovic-Talisman, T.; Burnette, D.T.; Lippincott-Schwartz, J.; Jones, G.E.; Heintzmann, R. Bayesian localization microscopy reveals nanoscale podosome dynamics. Nat. Methods 2012, 9, 195-200. [CrossRef]

38. Yahiatene, I.; Hennig, S.; Müller, M.; Huser, T. Entropy-based super-resolution imaging (ESI): From disorder to fine detail. ACS Photonics 2015, 2, 1049-1056. [CrossRef]

39. Deng, Y.; Sun, M.; Lin, P.H.; Ma, J.; Shaevitz, J.W. Spatial covariance reconstructive (SCORE) super-resolution fluorescence microscopy. PLoS ONE 2014, 9, e94807. [CrossRef]

40. Agarwal, K.; Macháň, R. Multiple signal classification algorithm for super-resolution fluorescence microscopy. Nat. Commun. 2016, 7, 13752. [CrossRef]

41. Holden, S.J.; Uphoff, S.; Kapanidis, A.N. DAOSTORM: An algorithm for high-density super-resolution microscopy. Nat. Methods 2011, 8, 279-280. [CrossRef] [PubMed]

42. Schermelleh, L.; Ferrand, A.; Huser, T.; Eggeling, C.; Sauer, M.; Biehlmaier, O.; Drummen, G.P.C. Super-resolution microscopy demystified. Nat. Cell Biol. 2019, 21, 72. [CrossRef] [PubMed]

43. Cloin, B.M.C.; Zitter, E.D.; Salas, D.; Gielen, V.; Folkers, G.E.; Mikhaylova, M.; Bergeler, M.; Krajnik, B.; Harvey, J.; Hoogenraad, C.C.; et al. Efficient switching of mCherry fluorescence using chemical caging. Proc. Natl. Acad. Sci. USA 2017, 114, 7013-7018. [CrossRef] [PubMed]

44. Winterflood, C.M.; Ewers, H. Single-molecule localization microscopy using mCherry. ChemPhysChem 2014, 15, 3447-3451. [CrossRef]

45. Tiwari, D.K.; Nagai, T. Smart fluorescent proteins: Innovation for barrier-free superresolution imaging in living cells. Dev. Growth Differ. 2013, 55, 491-507. [CrossRef] [PubMed]

46. Arai, Y.; Takauchi, H.; Ogami, Y.; Fujiwara, S.; Nakano, M.; Matsuda, T.; Nagai, T. Spontaneously blinking fluorescent protein for simple single laser super-resolution live cell imaging. ACS Chem. Biol. 2018, 13, 1938-1943. [CrossRef] [PubMed] 
47. Shinoda, H.; Lu, K.; Nakashima, R.; Wazawa, T.; Noguchi, K.; Matsuda, T.; Nagai, T. Acid-tolerant reversibly switchable green fluorescent protein for super-resolution imaging under acidic conditions. Cell Chem. Biol. 2019. [CrossRef]

48. Patterson, G.H.; Lippincott-Schwartz, J. A photoactivatable GFP for selective photolabeling of proteins and cells. Science 2002, 297, 1873-1877. [CrossRef]

49. Subach, F.V.; Patterson, G.H.; Manley, S.; Gillette, J.M.; Lippincott-Schwartz, J.; Verkhusha, V.V. Photoactivatable mCherry for high-resolution two-color fluorescence microscopy. Nat. Methods 2009, 6, 153-159. [CrossRef]

50. Wiedenmann, J.; Ivanchenko, S.; Oswald, F.; Schmitt, F.; Röcker, C.; Salih, A.; Spindler, K.D.; Nienhaus, G.U. EosFP, a fluorescent marker protein with UV-inducible green-to-red fluorescence conversion. Proc. Natl. Acad. Sci. USA 2004, 101, 15905-15910. [CrossRef]

51. Zhang, M.; Chang, H.; Zhang, Y.; Yu, J.; Wu, L.; Ji, W.; Chen, J.; Liu, B.; Lu, J.; Liu, Y.; et al. Rational design of true monomeric and bright photoactivatable fluorescent proteins. Nat. Methods 2012, 9, 727-729. [CrossRef] [PubMed]

52. Brakemann, T.; Stiel, A.C.; Weber, G.; Andresen, M.; Testa, I.; Grotjohann, T.; Leutenegger, M.; Plessmann, U.; Urlaub, H.; Eggeling, C.; et al. A reversibly photoswitchable GFP-like protein with fluorescence excitation decoupled from switching. Nat. Biotechnol. 2011, 29, 942-947. [CrossRef] [PubMed]

53. Andresen, M.; Stiel, A.C.; Fölling, J.; Wenzel, D.; Schönle, A.; Egner, A.; Eggeling, C.; Hell, S.W.; Jakobs, S. Photoswitchable fluorescent proteins enable monochromatic multilabel imaging and dual color fluorescence nanoscopy. Nat. Biotechnol. 2008, 26, 1035-1040. [CrossRef] [PubMed]

54. Ando, R.; Mizuno, H.; Miyawaki, A. Regulated fast nucleocytoplasmic shuttling observed by reversible protein highlighting. Science 2004, 306, 1370-1373. [CrossRef]

55. Acharya, A.; Bogdanov, A.M.; Grigorenko, B.L.; Bravaya, K.B.; Nemukhin, A.V.; Lukyanov, K.A.; Krylov, A.I. Photoinduced chemistry in fluorescent proteins: Curse or blessing? Chem. Rev. 2017, 117, 758-795. [CrossRef]

56. Isaacoff, B.P.; Li, Y.; Lee, S.A.; Biteen, J.S. SMALL-LABS: Measuring single-molecule intensity and position in obscuring backgrounds. Biophys. J. 2019, 116, 975-982. [CrossRef]

57. Geissbuehler, S.; Bocchio, N.L.; Dellagiacoma, C.; Berclaz, C.; Leutenegger, M.; Lasser, T. Mapping molecular statistics with balanced super-resolution optical fluctuation imaging (bSOFI). Opt. Nanoscopy 2012, 1, 4. [CrossRef]

58. Hertel, F.; Mo, G.C.H.; Duwé, S.; Dedecker, P.; Zhang, J. RefSOFI for mapping nanoscale organization of protein-protein interactions in living cells. Cell Rep. 2016, 14, 390-400. [CrossRef]

59. Nickerson, A.; Huang, T.; Lin, L.J.; Nan, X. Photoactivated localization microscopy with bimolecular fluorescence complementation (BiFC-PALM) for nanoscale imaging of protein-protein interactions in cells. PLoS ONE 2014, 9, e100589. [CrossRef]

60. Liu, Z.; Xing, D.; Su, Q.P.; Zhu, Y.; Zhang, J.; Kong, X.; Xue, B.; Wang, S.; Sun, H.; Tao, Y.; et al. Super-resolution imaging and tracking of protein-protein interactions in sub-diffraction cellular space. Nat. Commun. 2014, 5, 4443. [CrossRef]

61. Xia, P.; Liu, X.; Wu, B.; Zhang, S.; Song, X.; Yao, P.Y.; Lippincott-Schwartz, J.; Yao, X.; Zheng, Y. Superresolution imaging reveals structural features of EB1 in microtubule plus-end tracking. Mol. Biol. Cell 2014, 25, 4166-4173. [CrossRef] [PubMed]

62. Chen, M.; Liu, S.; Li, W.; Zhang, Z.; Zhang, X.; Zhang, X.-E.; Cui, Z. Three-fragment fluorescence complementation coupled with photoactivated localization microscopy for nanoscale imaging of ternary complexes. ACS Nano 2016, 10, 8482-8490. [CrossRef] [PubMed]

63. Wang, S.; Ding, M.; Chen, X.; Chang, L.; Sun, Y. Development of bimolecular fluorescence complementation using rsEGFP2 for detection and super-resolution imaging of protein-protein interactions in live cells. Biomed. Opt. Express 2017, 8, 3119-3131. [CrossRef] [PubMed]

64. Tebo, A.G.; Gautier, A. A split fluorescent reporter with rapid and reversible complementation. Nat. Commun. 2019, 10, 2822. [CrossRef] [PubMed]

65. Sharonov, A.; Hochstrasser, R.M. Wide-field subdiffraction imaging by accumulated binding of diffusing probes. Proc. Natl. Acad. Sci. USA 2006, 103, 18911-18916. [CrossRef] [PubMed]

66. Jungmann, R.; Steinhauer, C.; Scheible, M.; Kuzyk, A.; Tinnefeld, P.; Simmel, F.C. Single-molecule kinetics and super-resolution microscopy by fluorescence imaging of transient binding on DNA origami. Nano Lett. 2010, 10, 4756-4761. [CrossRef] 
67. De Keersmaecker, H.; Camacho, R.; Rantasa, D.M.; Fron, E.; Uji-i, H.; Mizuno, H.; Rocha, S. Mapping transient protein interactions at the nanoscale in living mammalian cells. ACS Nano 2018, 12, 9842-9854. [CrossRef]

68. Etheridge, T.J.; Boulineau, R.L.; Herbert, A.; Watson, A.T.; Daigaku, Y.; Tucker, J.; George, S.; Jönsson, P.; Palayret, M.; Lando, D.; et al. Quantification of DNA-associated proteins inside eukaryotic cells using single-molecule localization microscopy. Nucleic Acids Res. 2014, 42, e146. [CrossRef]

69. Chen, J.; Zhang, Z.; Li, L.; Chen, B.C.; Revyakin, A.; Hajj, B.; Legant, W.; Dahan, M.; Lionnet, T.; Betzig, E.; et al. Single-molecule dynamics of enhanceosome assembly in embryonic stem cells. Cell 2014, 156, 1274-1285. [CrossRef]

70. Cisse, I.I.; Izeddin, I.; Causse, S.Z.; Boudarene, L.; Senecal, A.; Muresan, L.; Dugast-Darzacq, C.; Hajj, B.; Dahan, M.; Darzacq, X. Real-time dynamics of RNA polymerase II clustering in live human cells. Science 2013, 341, 664-667. [CrossRef]

71. Cho, W.K.; Jayanth, N.; English, B.P.; Inoue, T.; Andrews, J.O.; Conway, W.; Grimm, J.B.; Spille, J.H.; Lavis, L.D.; Lionnet, T.; et al. RNA polymerase II cluster dynamics predict mRNA output in living cells. eLife 2016, 5, e13617. [CrossRef] [PubMed]

72. Loveland, A.B.; Habuchi, S.; Walter, J.C.; van Oijen, A.M. A general approach to break the concentration barrier in single-molecule imaging. Nat. Methods 2012, 9, 987-992. [CrossRef] [PubMed]

73. Peng, S.; Sun, R.; Wang, W.; Chen, C. Single-molecule photoactivation FRET: A general and easy-to-implement approach to break the concentration barrier. Angew. Chem. Int. Ed. Engl. 2017, 56, 6882-6885. [CrossRef] [PubMed]

74. Fox-Roberts, P.; Marsh, R.; Pfisterer, K.; Jayo, A.; Parsons, M.; Cox, S. Local dimensionality determines imaging speed in localization microscopy. Nat. Commun. 2017, 8, 13558. [CrossRef]

75. Owen, D.M.; Sauer, M.; Gaus, K. Fluorescence localization microscopy. Commun. Integr. Biol. 2012, 5, 345-349. [CrossRef]

76. Banterle, N.; Bui, K.H.; Lemke, E.A.; Beck, M. Fourier ring correlation as a resolution criterion for super-resolution microscopy. J. Struct. Biol. 2013, 183, 363-367. [CrossRef]

77. Mo, G.C.H.; Ross, B.; Hertel, F.; Manna, P.; Yang, X.; Greenwald, E.; Booth, C.; Plummer, A.M.; Tenner, B.; Chen, Z.; et al. Genetically encoded biosensors for visualizing live-cell biochemical activity at super-resolution. Nat. Methods 2017, 14, 427-434. [CrossRef]

78. Dickson, R.M.; Cubitt, A.B.; Tsien, R.Y.; Moerner, W.E. On/off blinking and switching behaviour of single molecules of green fluorescent protein. Nature 1997, 388, 355-358. [CrossRef]

79. Tiwari, D.K.; Arai, Y.; Yamanaka, M.; Matsuda, T.; Agetsuma, M.; Nakano, M.; Fujita, K.; Nagai, T. A fast- and positively photoswitchable fluorescent protein for ultralow-laser-power RESOLFT nanoscopy. Nat. Methods 2015, 12, 515-518. [CrossRef]

80. Wazawa, T.; Arai, Y.; Kawahara, Y.; Takauchi, H.; Washio, T.; Nagai, T. Highly biocompatible super-resolution fluorescence imaging using the fast photoswitching fluorescent protein Kohinoor and SPoD-ExPAN with Lp-regularized image reconstruction. Microscopy 2018, 67, 89-98.

81. Hafi, N.; Grunwald, M.; van den Heuvel, L.S.; Aspelmeier, T.; Chen, J.-H.; Zagrebelsky, M.; Schütte, O.M.; Steinem, C.; Korte, M.; Munk, A.; et al. Fluorescence nanoscopy by polarization modulation and polarization angle narrowing. Nat. Methods 2014, 11, 579-584. [CrossRef] [PubMed]

82. Rainey, K.H.; Patterson, G.H. Photoswitching FRET to monitor protein-protein interactions. Proc. Natl. Acad. Sci. USA 2019, 116, 864-873. [CrossRef] [PubMed]

83. Fosque, B.F.; Sun, Y.; Dana, H.; Yang, C.-T.; Ohyama, T.; Tadross, M.R.; Patel, R.; Zlatic, M.; Kim, D.S.; Ahrens, M.B.; et al. Labeling of active neural circuits in vivo with designed calcium integrators. Science 2015, 347, 755-760. [CrossRef] [PubMed]

84. McKinney, S.A.; Murphy, C.S.; Hazelwood, K.L.; Davidson, M.W.; Looger, L.L. A bright and photostable photoconvertible fluorescent protein. Nat. Methods 2009, 6, 131-133. [CrossRef]

85. Zolnik, T.A.; Sha, F.; Johenning, F.W.; Schreiter, E.R.; Looger, L.L.; Larkum, M.E.; Sachdev, R.N.S. All-optical functional synaptic connectivity mapping in acute brain slices using the calcium integrator CaMPARI. J. Physiol. 2017, 595, 1465-1477. [CrossRef]

86. Basu, S.; Needham, L.-M.; Lando, D.; Taylor, E.J.R.; Wohlfahrt, K.J.; Shah, D.; Boucher, W.; Tan, Y.L.; Bates, L.E.; Tkachenko, O.; et al. FRET-enhanced photostability allows improved single-molecule tracking of proteins and protein complexes in live mammalian cells. Nat. Commun. 2018, 9, 2520. [CrossRef] 
87. Duwé, S.; De Zitter, E.; Gielen, V.; Moeyaert, B.; Vandenberg, W.; Grotjohann, T.; Clays, K.; Jakobs, S.; Van Meervelt, L.; Dedecker, P. Expression-enhanced fluorescent proteins based on enhanced green fluorescent protein for super-resolution microscopy. ACS Nano 2015, 9, 9528-9541. [CrossRef]

88. Roebroek, T.; Duwé, S.; Vandenberg, W.; Dedecker, P. Reduced fluorescent protein switching fatigue by binding-induced emissive state stabilization. Int. J. Mol. Sci. 2017, 18, 2015. [CrossRef]

89. Kirchhofer, A.; Helma, J.; Schmidthals, K.; Frauer, C.; Cui, S.; Karcher, A.; Pellis, M.; Muyldermans, S.; Casas-Delucchi, C.S.; Cardoso, M.C.; et al. Modulation of protein properties in living cells using nanobodies. Nat. Struct. Mol. Biol. 2010, 17, 133-138. [CrossRef]

90. Eshaghi, M.; Sun, G.; Grüter, A.; Lim, C.L.; Chee, Y.C.; Jung, G.; Jauch, R.; Wohland, T.; Chen, S.L. Rational structure-based design of bright GFP-based complexes with tunable dimerization. Angew. Chem. Int. Ed. Engl. 2015, 54, 13952-13956. [CrossRef]

(C) 2019 by the authors. Licensee MDPI, Basel, Switzerland. This article is an open access article distributed under the terms and conditions of the Creative Commons Attribution (CC BY) license (http://creativecommons.org/licenses/by/4.0/). 